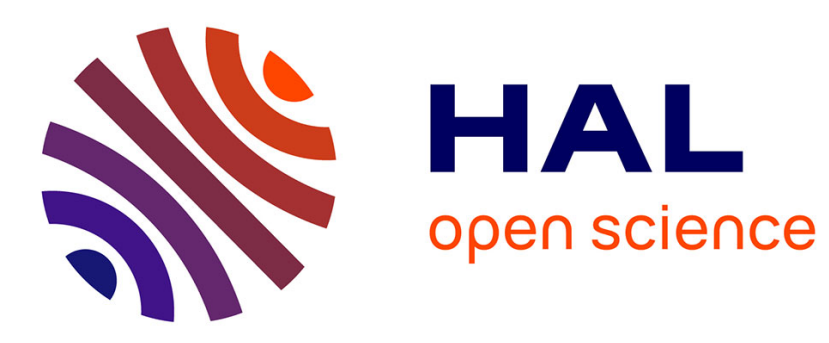

\title{
Atlantic Subsurface Temperatures: Response to a Shutdown of the Overturning Circulation and Consequences for Its Recovery
}

\author{
Juliette Mignot, Andrey Ganopolski, Anders Levermann
}

\section{- To cite this version:}

Juliette Mignot, Andrey Ganopolski, Anders Levermann. Atlantic Subsurface Temperatures: Response to a Shutdown of the Overturning Circulation and Consequences for Its Recovery. Journal of Climate, 2007, 20, pp.4884. 10.1175/JCLI4280.1 . hal-00770701

\section{HAL Id: hal-00770701 \\ https://hal.science/hal-00770701}

Submitted on 10 Jun 2021

HAL is a multi-disciplinary open access archive for the deposit and dissemination of scientific research documents, whether they are published or not. The documents may come from teaching and research institutions in France or abroad, or from public or private research centers.
L'archive ouverte pluridisciplinaire HAL, est destinée au dépôt et à la diffusion de documents scientifiques de niveau recherche, publiés ou non, émanant des établissements d'enseignement et de recherche français ou étrangers, des laboratoires publics ou privés. 


\title{
Atlantic Subsurface Temperatures: Response to a Shutdown of the Overturning Circulation and Consequences for Its Recovery
}

\author{
J. Mignot, $*$ A. Ganopolski, and A. Levermann ${ }^{+}$ \\ Potsdam Institute for Climate Impact Research, Potsdam, Germany
}

(Manuscript received 28 September 2006, in final form 13 February 2007)

\begin{abstract}
Using the coupled climate model of intermediate complexity, CLIMBER-3 $\alpha$, changes in the vertical thermal structure associated with a shutdown of the Atlantic meridional overturning circulation (AMOC) are investigated. When North Atlantic Deep Water formation is inhibited by anomalous freshwater forcing, intermediate depth ventilation can remain active and cool the subsurface water masses (i.e., the "cold case"). However, if intermediate ventilation is completely suppressed, relatively warm water coming from the south penetrates to a high northern latitude beneath the halocline and induces a strong vertical temperature inversion between the surface and intermediate depth (i.e., the "warm case"). Both types of temperature anomalies emerge within the first decade after the beginning of the freshwater perturbation. The sign of subsurface temperature anomaly has a strong implication for the recovery of the AMOC once the anomalous freshwater forcing is removed. While the AMOC recovers from the cold case on centennial time scales, the recovery is much more rapid (decadal time scales) when ventilation is completely suppressed and intermediate depths are anomalously warm. This is explained by a more rapid destabilization of the water column after cessation of the anomalous flux due to a strong vertical temperature inversion. A suite of sensitivity experiments with varying strength and duration of the freshwater perturbation and a larger value of background vertical diffusivity demonstrate robustness of the phenomenon. Implications of the simulated subsurface temperature response to the shutdown of the AMOC for future climate and abrupt climate changes of the past are discussed.
\end{abstract}

\section{Introduction}

Because of its importance for the climate system, the Atlantic meridional overturning circulation (AMOC) has received considerable attention in recent years (e.g., Vellinga and Wood 2002; Winton 2003; Herweijer et al. 2005). The AMOC is responsible for a large part of meridional heat transport in the Atlantic Ocean (e.g., Ganachaud and Wunsch 2000; Trenberth and Caron 2001) and numerous modeling experiments have shown that changes in its strength and spatial structure can considerably affect regional and global climate

\footnotetext{
* Current affiliation: LOCEAN, Unité Mixte de Recherché, CNRS-IRD-UPMC-MNHN, Université Pierre et Marie Curie, Paris, France.

+ Additional affiliation: Institute of Physics, Potsdam University, Potsdam, Germany.
}

Corresponding author address: J. Mignot, LOCEAN, Université Pierre et Marie Curie, Case courrier 100, 4 place Jussieu, 75252 Paris CEDEX 05, France.

E-mail: juliette.mignot@locean-ipsl.upmc.fr
(Crowley 1992; Stocker 1998; Vellinga and Wood 2002; Timmermann et al. 2005; Levermann et al. 2005). Rapid reorganizations of the AMOC are considered as the prime candidates for explaining abrupt climate changes recorded during glacial times (Clarke et al. 2002; Rahmstorf 2002). The possibility of an AMOC shutdown in the future in response to global warming has been demonstrated with a number of climate models (Manabe and Stouffer 1993; Rahmstorf and Ganopolski 1999; Houghton et al. 2001).

So-called water hosing experiments, where anomalous freshwater flux (or equivalent negative salinity flux) is applied to some regions of the ocean are widely used to study the stability of the AMOC and its impact on climate (e.g., Stocker and Wright 1991; Manabe and Stouffer 1995; Rahmstorf 1996; Fanning and Weaver 1997; Schiller et al. 1997; Rind et al. 2001; Rahmstorf et al. 2005; Stouffer et al. 2006). These idealized experiments are motivated by the necessity to understand past abrupt changes of the ocean circulation, as well as its response to future climate change. A large discharge of freshwater into the North Atlantic during glacial

DOI: 10.1175/JCLI4280.1

(C) 2007 American Meteorological Society 
time and deglaciation is believed to be responsible for major shifts in the ocean circulation recorded by various paleoclimate proxies (e.g., Bond et al. 1992; McManus et al. 2004). Concerning future climate change, model simulations suggest that global warming would intensify the freshwater input into the North Atlantic, as a consequence of an intensification of northward atmospheric moisture transport, increase of river discharge into the Arctic Ocean, and melting of the Greenland ice sheet (Church et al. 2001). Recent observations give consistent indications (Peterson et al. 2002; Dickson et al. 2002).

In most hosing experiments, anomalous freshwater flux has been applied to the North Atlantic and, in spite of differences in models, areas and magnitudes of the applied freshwater flux, a number of robust features of the models' response emerged. In particular, it has been shown that a sufficiently large anomalous freshwater flux [typically $0.1-1 \mathrm{~Sv}\left(1 \mathrm{~Sv}=10^{6} \mathrm{~m}^{3} \mathrm{~s}^{-1}\right)$, this value being strongly model dependent] can shut down the AMOC completely on decadal to centennial time scales (e.g., Rahmstorf et al. 2005; Stouffer et al. 2006). This leads to a strong surface oceanic and atmospheric cooling in the North Atlantic realm (order of $10 \mathrm{~K}$ ) and a pronounced cooling over most of the Northern Hemisphere. At the same time, in the southern Atlantic, surface and subsurface warming occurs on decadal time scales (i.e., the Atlantic seesaw; Crowley 1992) after the shutdown of the AMOC. These warm anomalies gradually propagate into high latitudes of the Southern Hemisphere. This process occurs on multicentennial time scales and is thus not clearly seen in short-term water hosing experiments (e.g., Rind et al. 2001). Apart from a direct atmospheric temperature response, the shutdown of AMOC leads to a pronounced reorganization of atmospheric circulation, in particular to a southward shift of the intertropical convergence zone, which results in large changes in precipitation in the Tropics [e.g., Manabe and Stouffer (1988); Vellinga and Wood (2002); Broccoli et al. (2006) in models; Peterson et al. (2000) using paleo-observations].

At the same time, experiments with different climate models reveal important discrepancies that have not received much attention and remain unexplained. It has been shown that the magnitude and time scale of the AMOC weakening in response to a fixed amount of anomalous freshwater depends, among other factors, on the location of the anomaly, with a stronger and more rapid response if the latter is applied directly in the area of deep-water formation as compared to a more southern perturbation (Rahmstorf 1996; Manabe and Stouffer 1997; Gregory et al. 2003; Goelzer et al. 2006). Furthermore, while the models agree on the sur- face cooling in the North Atlantic and the surface and subsurface warming in the southern and tropical Atlantic, different authors report subsurface temperature changes in the mid- and high latitudes of the North Atlantic of the opposite sign: Manabe and Stouffer $(1988,1997)$ and Rind et al. (2001) show strong negative temperature anomalies developing in mid- and high latitudes of the North Atlantic from the surface to the bottom, while Knutti et al. (2004) and Rühlemann et al. (2004) report on strong subsurface warming (with a magnitude of several degrees) within the upper 1000 $\mathrm{m}$ in the Atlantic northern high latitudes. Together with the surface cooling, this can induce significant reversed vertical temperature gradients. Apart from that, the rate of recovery differs strongly between model experiments (e.g., Stouffer et al. 2006).

It is natural that surface changes associated with a weakening or a complete shutdown of the AMOC attracted the primary attention, because they can directly affect the regional and global climate. However, as we will show below, subsurface temperature and salinity changes are important because they determine the mechanism and rate of the AMOC recovery after cessation of the anomalous freshwater flux. This plays a role in the interpretation of paleoclimate data and the understanding of mechanisms of past abrupt climate changes. For example, the strong vertical temperature inversion in high latitudes of the North Atlantic during stadial (cold) Atlantic events is crucial for the rapid onset of Dansgaard-Oeschger warm events simulated by Ganopolski and Rahmstorf (2001). They are also an essential element of the mechanism of self-sustained deep-decoupling oscillations found in some models. These have been proposed to explain millennium-scale climate variability during glacial times (Winton 1997; Shaffer et al. 2004).

Here, we show that opposite subsurface temperature patterns in the northern North Atlantic are obtained in experiments with different locations of freshwater perturbations. First, this result is interesting in the framework of model intercomparison. In all the experiments cited above, hosing is alternatively applied in the high northern latitudes (e.g., Stouffer et al. 2006), farther south in the subtropics (e.g., Rahmstorf et al. 2005) or in an intermediate region around $50^{\circ} \mathrm{N}$ (e.g., Knutti et al. 2004; Rühlemann et al. 2004), and results are usually compared without special care. We will show that different experimental setups can induce very different oceanic subsurface anomalies and AMOC recovery mechanisms. Second, we will discuss some paleoclimatic implications of subsurface response to changes in the AMOC. These changes might be relevant for the 
assessment of environmental impacts of a possible future AMOC reduction in response to global warming.

The model and experiments are described in section 2. Subsurface temperature anomalies are discussed in section 3 and implications for the AMOC recovery are discussed in section 4 . Robustness of the results to details of the perturbation and to oceanic mixing parameterization is tested in section 5. Results are discussed in section 6 .

\section{Model and experimental setup}

The model used in this study is the CLIMBER-3 $\alpha$ coupled climate model of intermediate complexity (Montoya et al. 2005). It consists of the Potsdam statistical-dynamical atmospheric model version 2 (POTSDAM-2; Petoukhov et al. 2000) coupled to a global, 24-layer ocean general circulation model based on the Geophysical Fluid Dynamics Laboratory (GFDL) Modular Ocean Model version 3 (MOM-3) code and to the dynamic and thermodynamic sea ice module of Fichefet and Maqueda (1997). The oceanic model has a horizontal resolution of $3.75^{\circ} \times 3.75^{\circ}$. It uses a weak background vertical diffusivity $(\kappa=0.1 \times$ $10^{-4} \mathrm{~m}^{2} \mathrm{~s}^{-1}$ ) and a second-order-moment advection scheme for tracers (Prather 1986) that strongly reduces numerical diffusivity (Hofmann and Maqueda 2006). A parameterization of boundary enhanced mixing depending both on near-bottom stratification and roughness of topography (Ledwell et al. 2000) is implemented, following Hasumi and Suginohara (1999). This leads locally to vertical diffusion coefficients of up to $10^{-4} \mathrm{~m}^{2} \mathrm{~s}^{-1}$ for example over rough topography. Instead of a grid-based horizontal diffusivity, an isopycnal diffusion coefficient of $\kappa_{\text {iso }}=1000 \mathrm{~m}^{2} \mathrm{~s}^{-1}$ is applied. In the upper layer, the K-profile parameterization (Large et al. 1994) is used in order to better represent the mixed layer. The atmospheric POTSDAM-2 model has a coarse horizontal resolution $\left(7.5^{\circ}\right.$ latitude and $22.5^{\circ}$ longitude) and is based on the assumption of a universal vertical structure of temperature and humidity, which allows reducing the three-dimensional description to a set of two-dimensional prognostic equations for temperature and humidity. Description of atmospheric dynamics is based on a quasigeostrophic approach and a parameterization of the zonally averaged meridional atmospheric circulation. The synoptic processes are parameterized as diffusion terms with a turbulent diffusivity computed from the atmospheric stability and horizontal temperature gradients. Heat and freshwater fluxes between the ocean and the atmosphere are computed on the oceanic grid and applied without any flux adjustments. The wind stress is computed as the sum of the National Centers for Environ-
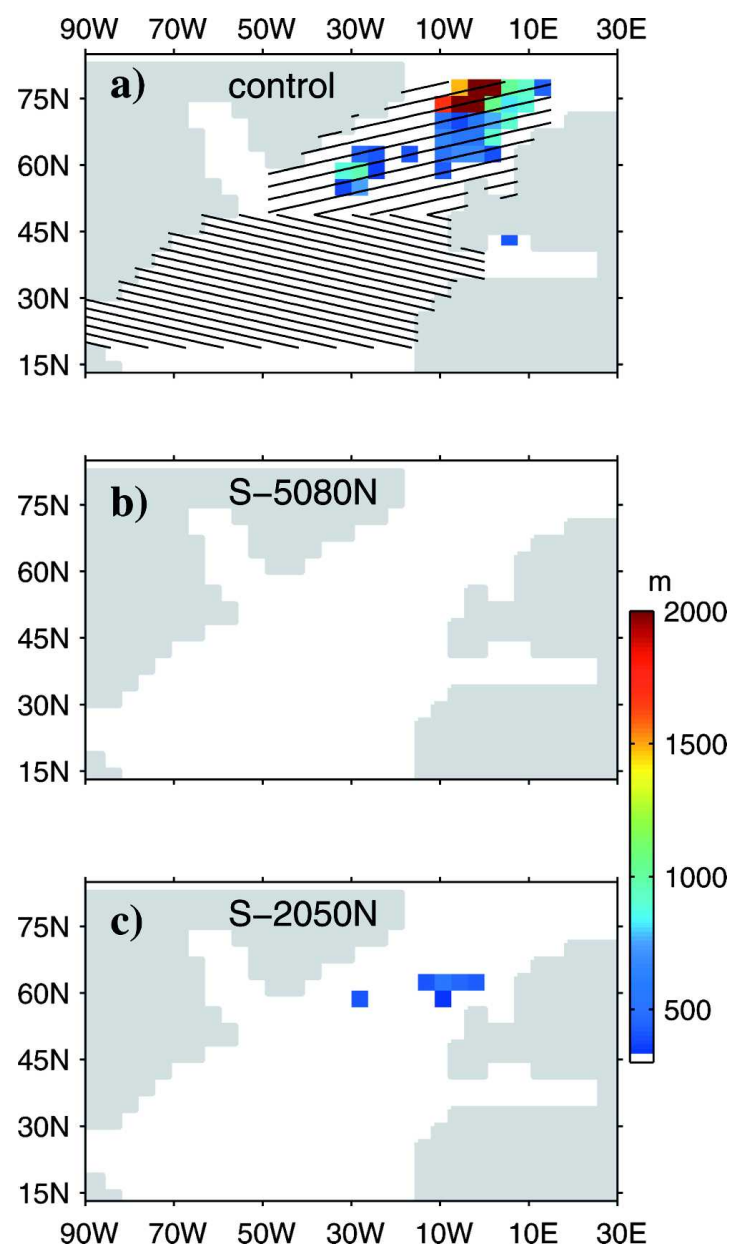

FIG. 1. Maximal depth of the turbulent mixed layer given by the model over the annual cycle in (a) the control run and in experiments (b) S-5080N and (c) S-2050N after $100 \mathrm{yr}$ of anomalous forcing. In (a), the hatched areas represent the two forcing areas used in the study (see text).

mental Prediction-National Center for Atmospheric Research (NCEP-NCAR) reanalysis wind stress climatology (Kalnay et al. 1996) and the wind stress anomaly calculated by the atmospheric model relative to the control run. The reader is referred to Montoya et al. (2005) for a description of the coupling and more details on the oceanic mixing parameterization, and to Mignot et al. (2006) for a discussion on the model's sensitivity to oceanic vertical diffusivity.

The control model run has been integrated under present-day boundary conditions for more than $5000 \mathrm{yr}$. It yields an overturning circulation in the Atlantic of about $12 \mathrm{~Sv}$, with deep-water formation occurring both in the Nordic Seas and in the Irminger Sea south of the Greenland-Scotland ridge (Fig. 1a). Note that it reaches much shallower depths in this latter area. Two specific experiments that differ in the location where the forcing is applied constitute the core of the study 

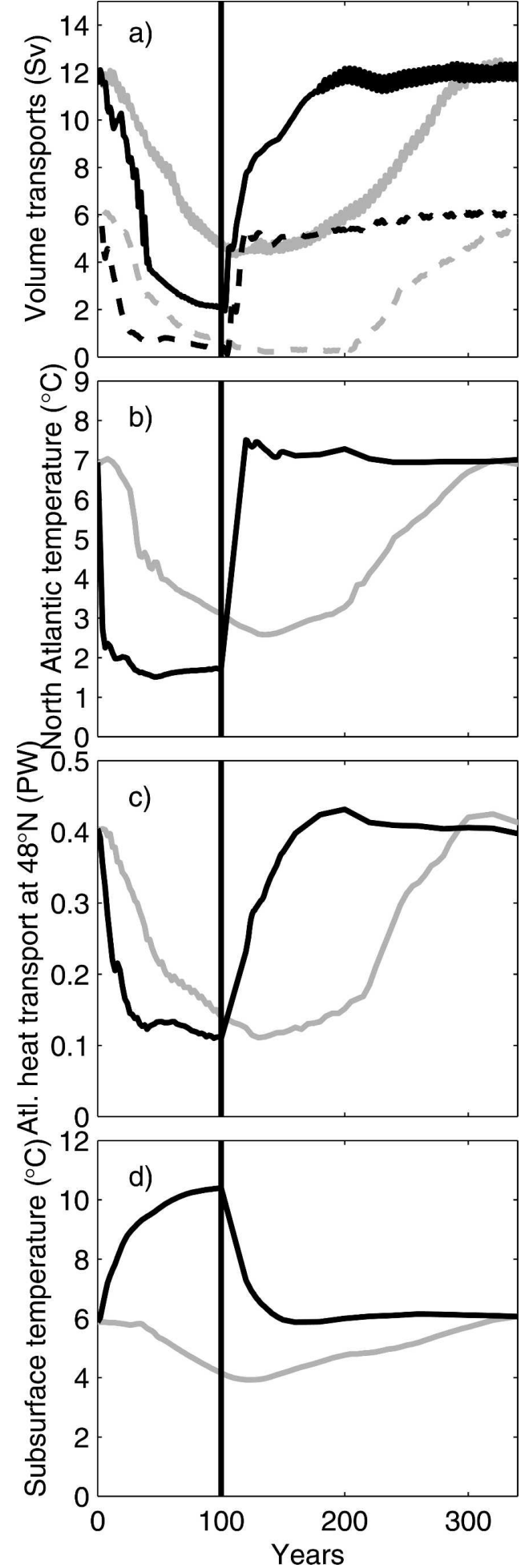

FIG. 2. (a) Time series of the maximum overturning circulation (solid) and overflow over the Greenland-Scotland ridge (dashed) annual averages in experiments S-2050N (cold case, gray) and S-5080N (warm case, black), respectively. The perturbation (equivalent to a freshwater flux of $0.35 \mathrm{~Sv}$ ) was applied during 100 yr (black vertical line) before being removed. (b)-(d) The cor-
(Fig. 1a). Note that in all experiments, in spite of the fact that the model uses an explicit free surface, the perturbation consists in an extraction of salt, so that the volume of the ocean is unperturbed. In the first experiment (S-5080N), a negative anomalous salt flux corresponding to $0.35 \mathrm{~Sv}$ of freshwater flux was uniformly added in the high latitudes of the North Atlantic, between $50^{\circ}$ and $80^{\circ} \mathrm{N}$. This region covers the sites of deep-water formation in the model. This setup is similar to the one of the Coupled Model Intercomparison Project (CMIP; Stouffer et al. 2006). In the second experiment (S-2050N), an anomalous salt flux of identical amplitude $(0.35 \mathrm{~Sv})$ was added to the North Atlantic between $20^{\circ}$ and $50^{\circ} \mathrm{N}$. This region is located south of the deep-water formation sites and was used by several authors to investigate the possible bistability of the meridional overturning circulation (e.g., Wang 2005; Rahmstorf et al. 2005). Note that since the forcing areas differ in both experiments, the anomalous flux imposed at each grid cell (expressed in $\mathrm{m} \mathrm{s}^{-1}$ ) differs. Both experiments were integrated for $100 \mathrm{yr}$ with anomalous forcing and an additional $300 \mathrm{yr}$ without the forcing. Additional experiments were performed in order to investigate the sensitivity of the results to the strength and duration of the freshwater perturbation and to the oceanic vertical diffusivity. Details will be given below.

\section{Subsurface temperature anomalies}

After $100 \mathrm{yr}$ of integration with $0.35-\mathrm{Sv}$ anomalous equivalent freshwater flux, the AMOC is strongly reduced in both experiments. Deep-water formation in the Nordic Seas and south of the Greenland-Scotland ridge has ceased, as can be inferred from the very shallow mixed layer depth in Figs. 1b,c compared to the control run (Fig. 1a). In the case of the southern forcing region (S-2050N), ventilation down to about 600-m depth is still enabled around $60^{\circ} \mathrm{N}$ (Fig. 1c). This is much shallower than the maximum depths reached in the control simulation (more than 2000 m, Fig. 1a) and does not result in deep-water formation. The time scale for the AMOC shutdown also differs in the two experiments, as seen in Fig. 2a: it is much more abrupt in experiment S-5080N where deep-water formation sites are directly capped by the surface freshwater anomaly.

$\leftarrow$

responding time series for the surface air temperature in the North Atlantic region $\left(60^{\circ}-90^{\circ} \mathrm{N}\right)$, the Atlantic ocean heat transport at $48^{\circ} \mathrm{N}$, and the Atlantic subsurface temperature averaged between $40^{\circ}$ and $80^{\circ} \mathrm{N}$ and between 100 and $700 \mathrm{~m}$ for the two experiments, respectively. 

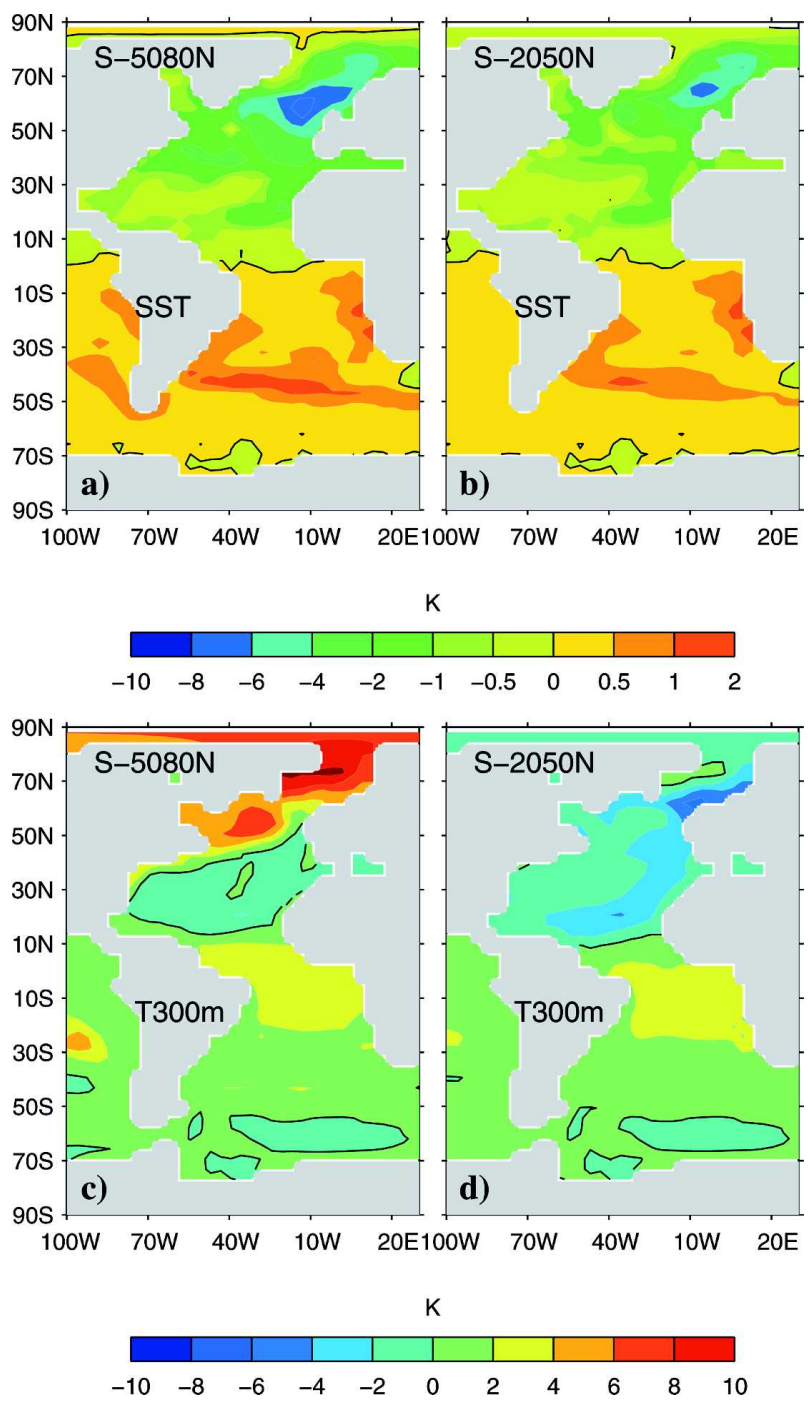

FIG. 3. Sea surface temperature anomaly in the Atlantic after $100 \mathrm{yr}$ of anomalous forcing as compared to the control run in experiments (a) S-5080N (warm case) and (b) S-2050N (cold case), respectively. The black contour lines represent $0 \mathrm{~K}$. (c), (d) Same as (a), (b), but for the temperature at 300-m depth.

In S-2050N, the freshwater-induced salinity anomalies are carried to the north by the oceanic circulation itself (e.g., Goelzer et al. 2006). This is why time scales are longer while the amplitude of the reduction is smaller (see also Rahmstorf 1996; Manabe and Stouffer 1997).

The pattern of sea surface temperature difference to the control run is qualitatively the same for both experiments (Figs. 3a,b), and corresponds to the classic picture associated with a reduction of the northward oceanic heat transport [e.g., Manabe and Stouffer (1988) in equilibrium experiments; Vellinga and Wood (2002) in transient experiments]: the South Atlantic is warmer than the control run by $0.5-2 \mathrm{~K}$ while a cooling

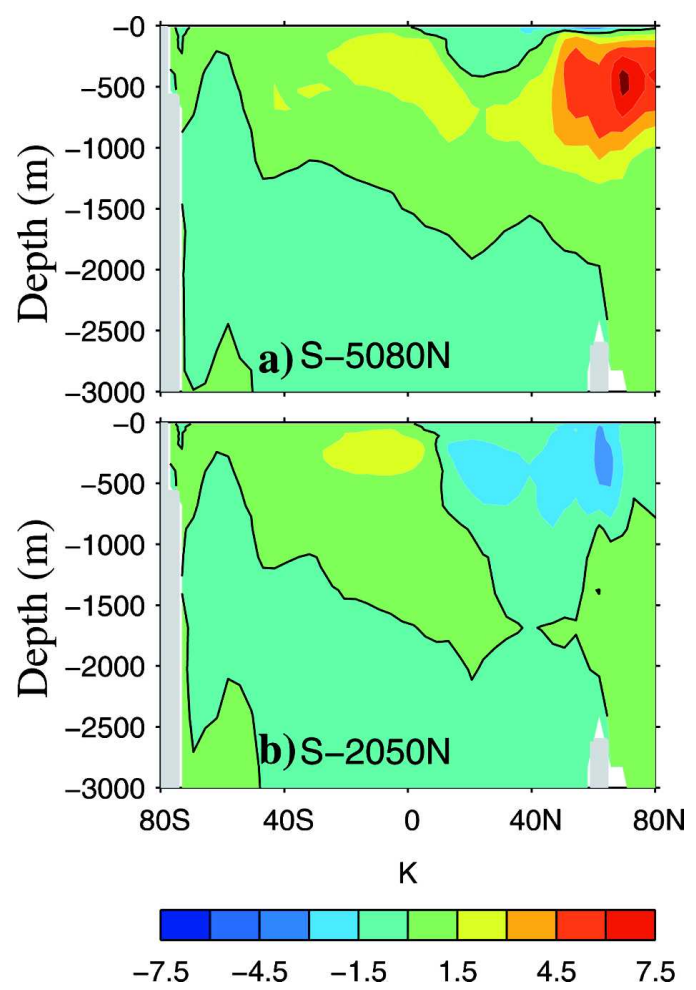

FIG. 4. Zonally averaged temperature anomaly in the Atlantic after $100 \mathrm{yr}$ of anomalous forcing in experiments (a) S-5080N (warm case) and (b) S-2050N (cold case), respectively, as compared to the control run. The black contour line represents $0 \mathrm{~K}$.

of up to $8 \mathrm{~K}$ occurs in the North Atlantic. In the latter basin, cooling is maximal $(12 \mathrm{~K}$ in S-5080N and $10 \mathrm{~K}$ in $\mathrm{S}-2050 \mathrm{~N}$ ) in the deep-water formation regions as a result of the shutdown of deep convection. The anomalous surface air temperature show the same qualitative north-south dipole, with maximum amplitude over the Nordic Seas being higher in S-5080N, as shown in Fig. 2b.

On the other hand, strong differences between the two experiments arise at an intermediate depth in the northern North Atlantic (Figs. 3c,d). In the S-2050N experiment, temperature anomalies at $300 \mathrm{~m}$ are of the same sign as surface anomalies. In S-5080N, a strong warm anomaly is found north of $50^{\circ} \mathrm{N}$. In the North Atlantic Tropics and subtropics, the waters at $300 \mathrm{~m}$ are colder than in the control run, but the anomaly is much reduced as compared to $\mathrm{S}-2050 \mathrm{~N}$ at corresponding latitudes. Southern Atlantic subsurface is anomalously warm in both experiments.

The zonally averaged fields further document these Atlantic subsurface temperature anomalies (Fig. 4). The warming of the northern North Atlantic in $\mathrm{S}-5080 \mathrm{~N}$ is maximal between 300 and $700 \mathrm{~m}$, and reaches more than $8 \mathrm{~K}$ locally. We will refer to this 

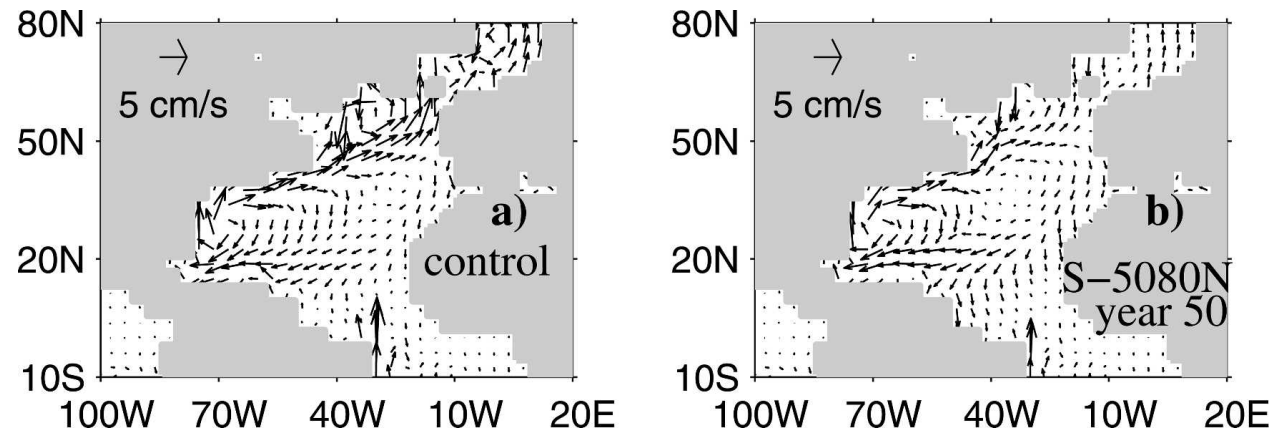

FIG. 5. Horizontal oceanic currents at 300-m depth in (a) the control run and (b) $50 \mathrm{yr}$ after the beginning of the perturbation in experiment S-5080N.

situation as the "warm case." Together with a strong surface cooling, this implies vertical temperature inversions of more than $10 \mathrm{~K}$ within the upper $300 \mathrm{~m}$. When the forcing is applied between $20^{\circ}$ and $50^{\circ} \mathrm{N}$, the cold surface anomalies reach down to about 1000-m depth ("cold case"). They are maximal above 600-m depth, which is approximately the pycnocline depth in the control run (Mignot et al. 2006).

The fundamental difference between the two experiments arises from different ventilation patterns and emerges already during the first years after the beginning of the perturbation (Fig. 2d). In the high-latitude forcing case (S-5080N, warm case), ventilation is rapidly and completely suppressed in the northern North Atlantic (Fig. 1b). Without any contact to the surface, the intermediate waters of the northern North Atlantic are protected from intense atmospheric cooling. On the other hand, the wind-induced circulation still enables ventilation in the tropical and subtropical Atlantic (e.g., Luyten et al. 1983) and northward transport of warm waters. This pathway is illustrated in Fig. 5b showing the horizontal circulation in the North Atlantic at 300-m depth $50 \mathrm{yr}$ after the beginning the perturbation. It can be shown that this circulation pattern is established within the first decades after the beginning of the perturbation and then remains stable as long as the freshwater is applied. Obviously, the intergyre connection is strongly reduced as compared to the initial state with an active AMOC (Fig. 5a), but it still exists. However, in the absence of convection, surface heat loss is drastically reduced and this small transport of warm waters from the south is sufficient to distort the vertical isotherms resulting from deep-water formation in the control run. This explains the warm subsurface anomaly seen in Figs. 3c and Fig. 4a. In the cold case (S-2050N), on the other hand, ventilation of intermediate layers around $60^{\circ} \mathrm{N}$ (Fig. 1c) is sufficient for the surface cooling to reach intermediate depths (Fig. 4b). The reduction of the cross-equatorial heat transport ex- plains surface and subsurface warming in the South Atlantic in both experiments.

The intermediate depth ventilation around $60^{\circ} \mathrm{N}$ also impacts the anomalous salinity structure of the Atlantic (Fig. 6a): in the warm case, the negative salinity anomaly imposed at the surface rather remains strictly confined to the upper $200 \mathrm{~m}$. Below this upper layer, water masses are anomalously salty as compared to the control run. This results from northward advection of tropical waters, the same mechanism that induces the warm subsurface anomalies (e.g., Fig. 6b). In the cold case, the negative salinity anomaly penetrates down through ventilation to about 1000-m depth (Fig. 6a), as does the negative temperature anomaly (Fig. 6b). The fact that the subtropical anomaly reaches the high latitudes after subduction also contributes to the subsurface fresh anomaly in Fig. 6a. However, this does not explain the cold temperature anomaly in Fig. 6b. Finally, the vertical density structure from the two experiments is rather similar below the surface layer (Fig. 6c): the deep and intermediate water masses in the North Atlantic are slightly lighter than in the control run, because of the warm anomaly in the warm case (S-5080N) and of the fresh anomaly in the cold case (S-2050N). Note that Levermann and Griesel (2004) showed that the pycnocline depth is stable under hosing perturbations in the model.

\section{Consequences for the recovery of the AMOC}

The preindustrial climate as simulated by the control run of CLIMBER- $3 \alpha$ is monostable in response to the water flux anomalies imposed here: the AMOC recovers as soon as the anomalous salt forcing is removed. Time series of this recovery are yet very different in the two experiments (Fig. 2a). The resumption from the warm case is abrupt and very fast (decadal time scales), while it is much more gradual (centennial time scales) for the cold case. As seen from Fig. 2, the average 


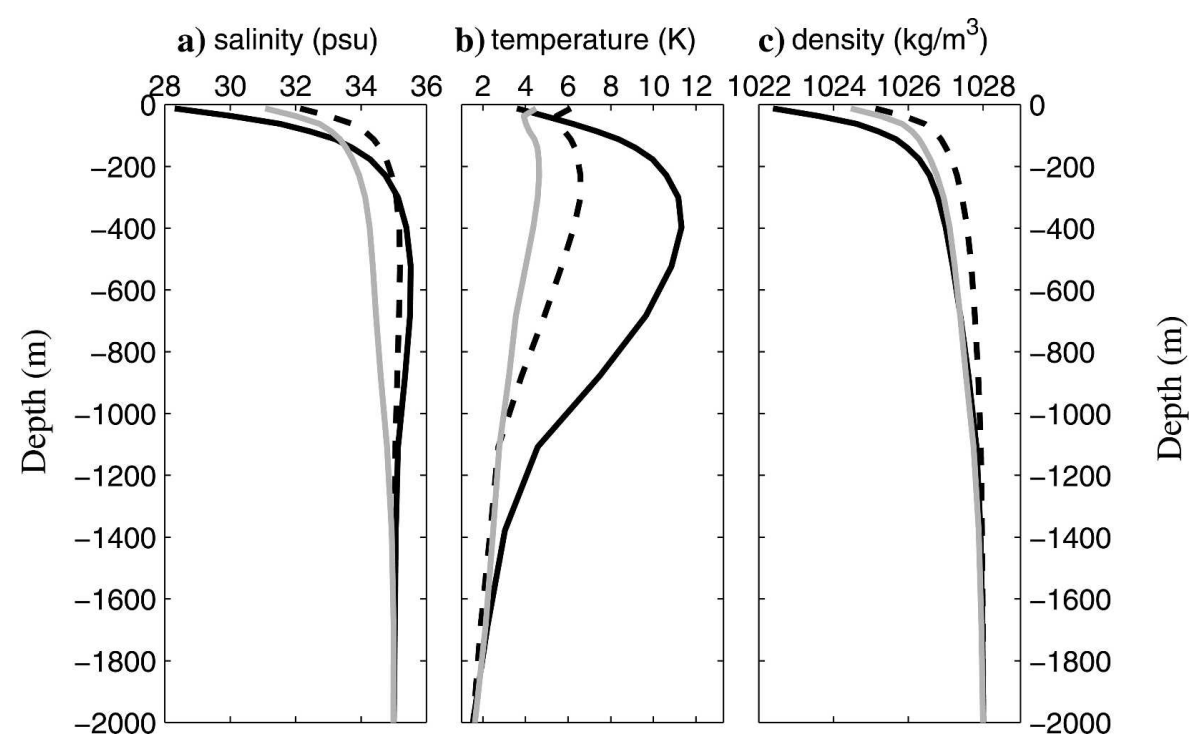

FIG. 6. (a) Salinity, (b) temperature, and (c) density profiles averaged in the Atlantic between $40^{\circ}$ and $80^{\circ} \mathrm{N}$ after $100 \mathrm{yr}$ of anomalous forcing in the Atlantic northern high latitudes (warm case, black lines) and in the Atlantic midlatitudes (cold case, gray lines). The dashed black line shows the same profiles in the control run.

surface air temperature in the North Atlantic (Fig. 2b) and the oceanic heat transport in the Atlantic at $48^{\circ} \mathrm{N}$ (Fig. 2c) closely follow the recovery of the AMOC (Fig. 2a). Salinity stratification is in fact much less favorable for the recovery in the warm case because of a much more pronounced halocline (Fig. 6a). In the absence of meridional heat transport, this difference in recovery time scales must thus result from the difference in temperature stratification.

In the warm case, sea surface salinity (SSS) in the hosing area starts to increase rapidly after the cessation of the anomalous freshwater flux, while SST changes little (Fig. 7c). This leads to an increase of mixed layer density that eventually exceeds that of the underlying layer. Convection starts first in the area where the SSS anomalies are smallest (compared to surrounding area) and the temperature inversion is strongest. These conditions are met in the area of strong wind-driven upwelling southeast of Greenland (Fig. 7a). Here, the mixed layer depth reaches several hundred meters already a few months after the cessation of anomalous freshwater flux (Fig. 8a, years 102-105). Consequently, the subsurface layer cools rapidly through air-sea interactions. Convection thus gradually weakens as the subsurface reservoir is damped, while it starts again in a more northward location (Fig. 8a, years 105-107). This is still not sufficient to switch deep convection on permanently (Fig. 8a, years 108-110), but it has enabled an increase of the density of intermediate water masses in the northern North Atlantic by cooling the relatively salty water mass (Fig. 9). This increases the meridional density gradient and drives the AMOC recovery. A weak circulation and shallow ventilation (Fig. 8a, around year 110) then brings salty water to high latitudes. As the fresh anomaly has at least partly been evacuated by the early convective spikes, it only takes about a decade for full deep convection to recover in the Nordic Seas. Note that the recovery of Atlantic overflow in S-5080N experiment starts simultaneously with the increase of the AMOC and reaches its full strength already during the first decade after the end of the hosing experiment.

The situation is very different in the experiment S-2050N where ventilation operates only south of the sill for $200 \mathrm{yr}$ after the end of hosing. It is only then that the convection resumes north of the sill and that the overflow starts to recover (Fig. 8b). In this experiment, the persisting intermediate depth ventilation around $60^{\circ} \mathrm{N}$ is enough to progressively evacuate the fresh surface anomaly, reestablish the northward density gradient, and allow the circulation to slowly intensify (Fig. 2a). This is a relatively slow process because unlike temperature, salinity is a conservative tracer that can only be evacuated by ocean circulation. Advection of salt from the Tropics by the resuming overturning circulation itself further contributes to this gradual recovery (e.g., Stommel 1961). However, since the freshwater perturbation was applied in the subtropics, at least part of it subducted in the center of the subtropical gyre. Therefore, the subtropical waters advected by the 

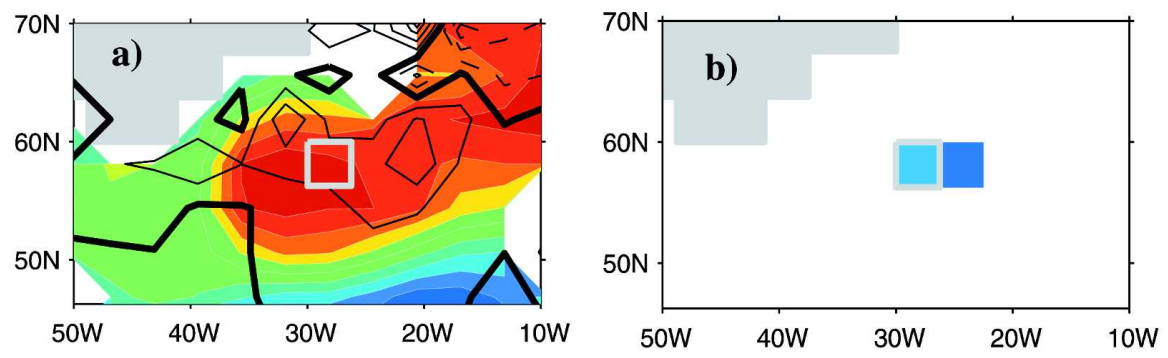

$\mathrm{K}$
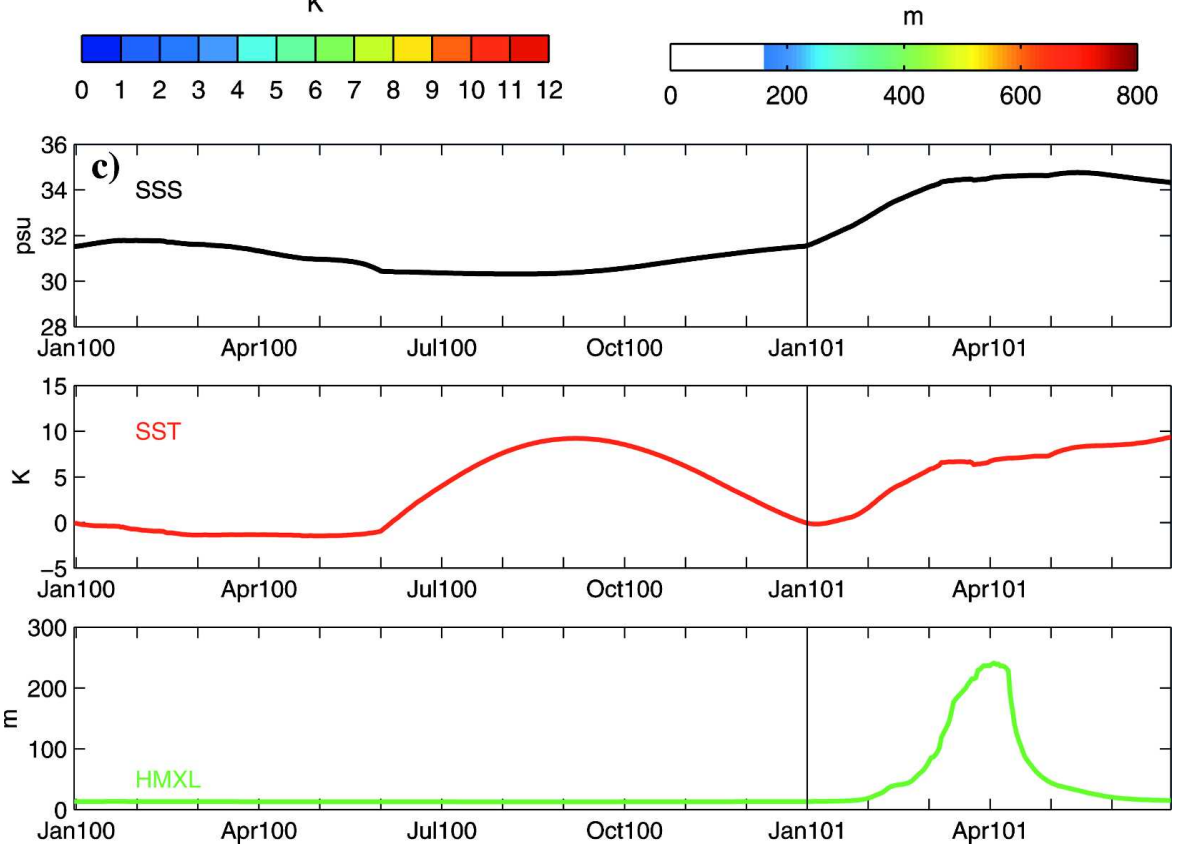

FIG. 7. Resumption mechanism in S-5080N. (a) (colors) Difference between SST and temperature at $300 \mathrm{~m}$ at year 100, i.e., at the end of the perturbation; a positive difference corresponds to subsurface temperatures warmer than SST. (contours) Curl of the wind stress in winter (January-March) of the first year after the end of the perturbation; continuous (dashed) contours are for positive (negative) values and are every $1 \times 10^{-8} \mathrm{dyn}^{-3}$ with the zero line in bold. Positive wind stress curl corresponds to upward Ekman velocity (upwelling). (b) Maximum oceanic mixed layer depth during the first winter of year 101, i.e., the year following the end of the perturbation. (c) Sea surface salinity, sea surface temperature, and turbulent mixed layer depth evolution at grid box marked in gray in (a), (b). The end of the perturbation is marked with the vertical black line at Jan101.

resuming circulation itself are not as salty as in the warm case. This further delays the recovery. The mixed layer gradually deepens during this slow process. More than $200 \mathrm{yr}$ after the cessation of the perturbation, mixed layer depths exceed $1200 \mathrm{~m}$ both in the Irminger and Nordic Seas. It further deepens in the Nordic Seas during the following $100 \mathrm{yr}$.

The gradual recovery of the AMOC from the cold case thus occurs through the progressive deepening of initially shallow ventilation in high latitudes and evacuation of the freshwater locally while the intensifying circulation further evacuates the freshwater that was added in the subtropics and progressively brings rela- tively salty tropical waters to the north. Note that the cyclonic wind forcing and the associated Ekman upwelling operates essentially equally in both experiments. However, in the cold case, it is not sufficient to induce an abrupt recovery because stability of the water column is strongly maintained by the subsurface cold anomalies. In the warm case, it is combined with the strong vertical temperature inversion that facilitates destabilization of the water column. Note also that in the warm case, convection starts as soon as a few months after the end of the perturbation. This initial fast response is inconsistent with a purely advective mechanism. It is rather due to an initial destabilization of the 

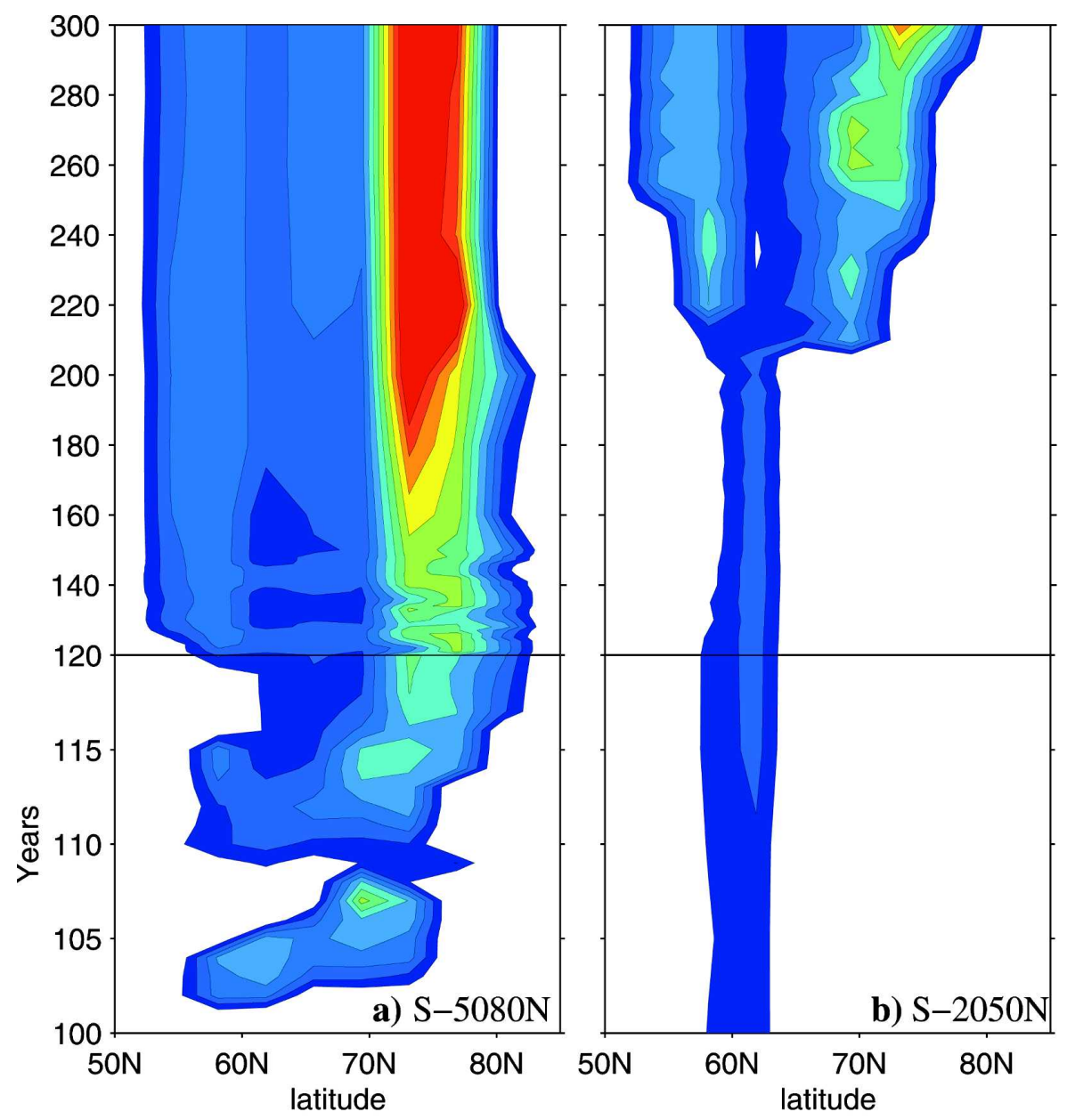

$\mathrm{m}$

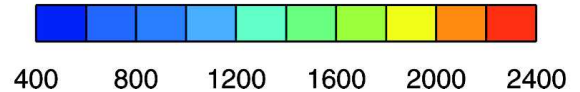

FIG. 8. Latitude-time evolution of maximum mixed layer depth in the northern North Atlantic for experiment (a) S-5080N (warm case) and (b) S-2050N (cold case). Note the change of time scale at year 120. In (a), contours are interpolated from yearly data until year 150 and from data sampled every $20 \mathrm{yr}$ from year $160 \mathrm{on}$. In (b), snapshot results recorded every $5 \mathrm{yr}$ are used.

water column as explained above. Only then does the salt advection mechanism come into play. The latter is more efficient in the warm case since saltier subtropical waters were less affected by the freshwater perturbation.

The dynamics of the AMOC recovery is thus very different in both experiments, yielding time scales of the order of decades in the warm case and centuries in the cold case. In the next section, we analyze the robustness of these findings to details of the experimental setup, namely, the magnitude and duration of the perturbation, its time evolution, and the oceanic vertical diffusivity.

\section{Sensitivity analysis}

Let us first investigate the sensitivity of the results to the magnitude of anomalous freshwater flux imposed on the North Atlantic. Experiments similar to the ones described above were performed with an anomalous salt flux equivalent to $0.1,0.2$, and $0.5 \mathrm{~Sv}$ of freshwater, respectively. The same types of anomalies develop in all cases, irrespective of the forcing magnitude (Fig. 10a). The magnitude of the anomaly increases with the strength of the perturbation. This increase is rather linear in the cold case while it saturates for strong perturbations in the warm case. The warm anomaly is the 


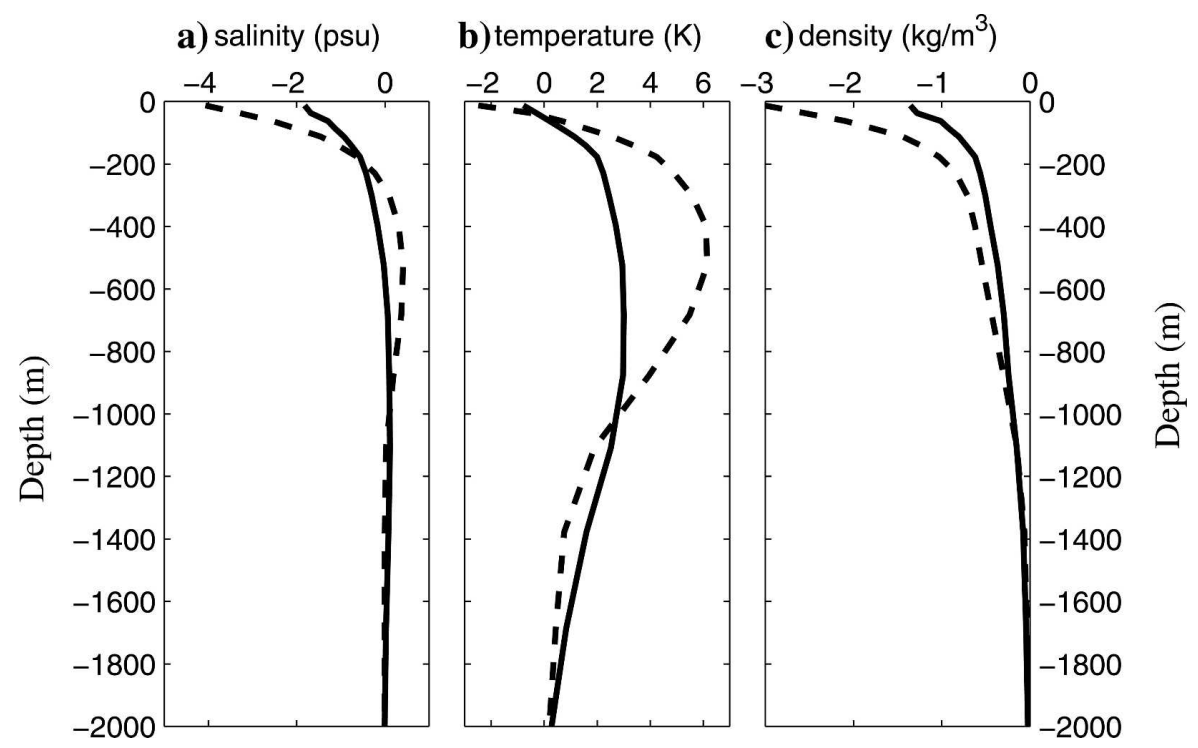

FIG. 9. Anomalous (a) salinity, (b) temperature, and (c) density profiles in the warm case. The profiles are Atlantic averages between $55^{\circ}$ and $80^{\circ} \mathrm{N}$ and computed as the difference to the control run. The dashed line shows the anomalous profile after $100 \mathrm{yr}$ of anomalous forcing and the continuous line is at year 110, i.e., $10 \mathrm{yr}$ after the end of the perturbation.

result of a balance between horizontal circulation and diffusion. The saturation can be understood through the maximum distortion of isotherms that can be induced by this balance. The AMOC recovery time is always longer in the corresponding cold case (Fig. 10b). In the warm case, it is of the order of a few decades for all the perturbation magnitudes that we tested. In the cold case, it increases approximately linearly with the magnitude of the perturbation and is of the order of one to two centuries.

An additional pair of experiments was performed to investigate the sensitivity of the results to the perturbation duration. Figure 11 shows the response of AMOC and overflow to $0.35 \mathrm{~Sv}$ of anomalous freshwater imposed over $1000 \mathrm{yr}$. This experiment is admittedly rather extreme but it shows that qualitative differences between the cold (gray) and warm (black) cases are the same as for shorter perturbations (cf. Fig. 2). Subsurface temperature anomalies are slightly stronger in case of a longer forcing (Fig. 10a, open circles), because the equilibrium is not reached in the shorter experiments $(100 \mathrm{yr})$. This supports the fact that the sign of subsurface temperature changes is not a transient effect and does not depend on the duration of the water hosing. It is an important point in order to compare the results to previous work. More discussion is given in section 6. In the cold case, time needed for the AMOC to recover $80 \%$ of its initial value is slightly longer than in the 100-yr perturbation experiment (Fig. 10b, open circles).
In the warm case, it is even shorter and the AMOC overshoots before eventually stabilizing.

The steplike forcing scenarios applied above are extremely simplified, and probably not realistic to represent, for example, the massive discharges of icebergs that are believed to have taken place in the past (e.g., Heinrich 1988). A freshwater input increasing and decreasing more progressively with time (e.g., linearly) is less straightforward in terms of interpretation but probably more realistic. Several experiments were carried out with such forcing scenarios, and Fig. 12 shows that the results presented above are robust: in the warm case, both the shutdown and the recovery of the AMOC are much more abrupt than in the cold one. Note that the recovery begins before the perturbation ceases completely. It only requires that the imposed freshwater anomaly is weaker than a threshold value that can be counteracted by the ventilation and the circulation itself in the cold case and the temperatureinduced destabilization of the water column associated to wind-driven upwelling in the warm case, as explained in section 4.

Finally, robustness of the results to the oceanic vertical diffusivity $\kappa$ was tested. No qualitative differences in the results were found when the standard background value $\kappa=0.1 \times 10^{-4} \mathrm{~m}^{2} \mathrm{~s}^{-1}$ was increased to $\kappa=0.3 \times 10^{-4} \mathrm{~m}^{2} \mathrm{~s}^{-1}$ (Fig. 10, triangles). Maximum subsurface temperature anomalies are of the same order of magnitude. Recovery time scales are also well 

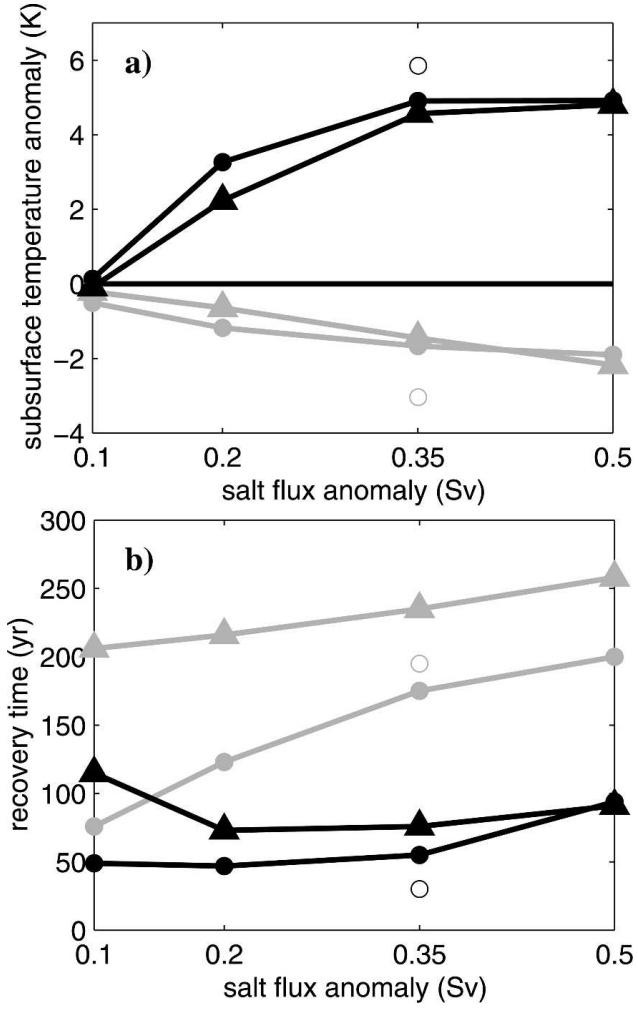

FIG. 10. (filled circles) (a) Subsurface temperature anomaly averaged in the North Atlantic between $40^{\circ}$ and $80^{\circ} \mathrm{N}$ and between 300- and 700-m depth and (b) time (years) needed for the AMOC to reach $80 \%$ of its initial value after cessation of anomalous freshwater flux in experiments S-2050N (cold case, gray) and S-5080N (warm case, black), respectively, with different magnitudes of the freshwater anomaly. For each experiment, the anomaly has been applied for $100 \mathrm{yr}$. (open circles) Same but for the experiments where the $0.35 \mathrm{~Sv}$ of equivalent freshwater anomaly are applied during $1000 \mathrm{yr}$. (triangles) Same as filled circles, but with an increased oceanic vertical diffusivity $(\kappa=$ $\left.0.3 \times 10^{-4} \mathrm{~m}^{2} \mathrm{~s}^{-1}\right)$.

separated for both experiments. It is larger by up to 50 $\mathrm{yr}$ in S-5080N and by $75 \mathrm{yr}$ in S-2050N for $\kappa=0.3 \times$ $10^{-4} \mathrm{~m}^{2} \mathrm{~s}^{-1}$ as compared to $\kappa=0.1 \times 10^{-4} \mathrm{~m}^{2} \mathrm{~s}^{-1}$.

These findings give us confidence in the robustness of the results. A discussion of the applicability of our results to other models and to the findings of previous studies is given in section 6 .

\section{Conclusions and discussion}

We used the coupled climate model CLIMBER-3 $\alpha$ to investigate the vertical thermal structure in the Atlantic following a cessation of deep-water formation. For this, we analyzed several experiments where a surface freshwater perturbation was applied either in the high latitudes of the North Atlantic (over the deep con-

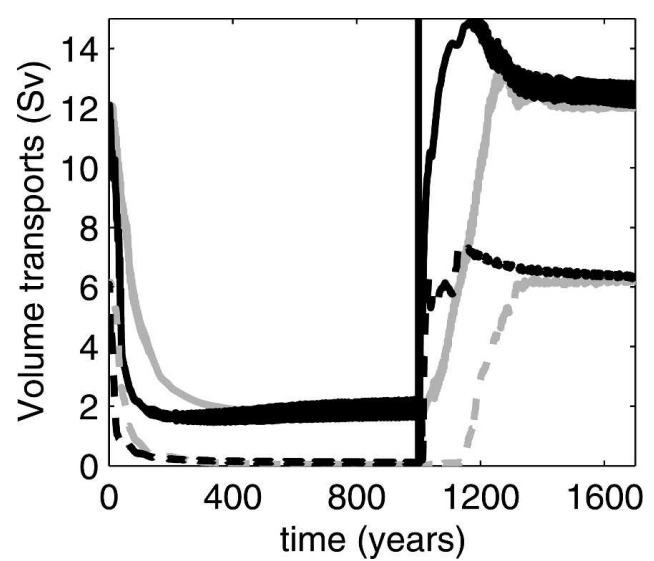

FIG. 11. As in Fig. 2a, but when the anomalous forcing is applied for $1000 \mathrm{yr}$.

vection sites) or in the Atlantic midlatitudes. We found that although both experiments lead to a rapid shutdown of deep-water formation and the AMOC and to a surface cooling in the North Atlantic, they induce radically different subsurface temperature anomalies, depending on the possibility for intermediate depth ventilation to take place or not. When the latter is suppressed, the subsurface waters in the North Atlantic are completely isolated from the cold atmosphere in the northern North Atlantic and only the subtropical ventilation is active. Propagation of warm water masses at the intermediate depth into the northern North Atlantic leads to robust warm subsurface anomalies and the development of a strong vertical temperature inversion in the Nordic Seas (warm case). In the case of active intermediate depth ventilation, subsurface waters are cooled by contact with the atmosphere (cold case).

These two cases have been observed in previous studies: Manabe and Stouffer (1997) and Rind et al. (2001) reported a subsurface cooling in response to the

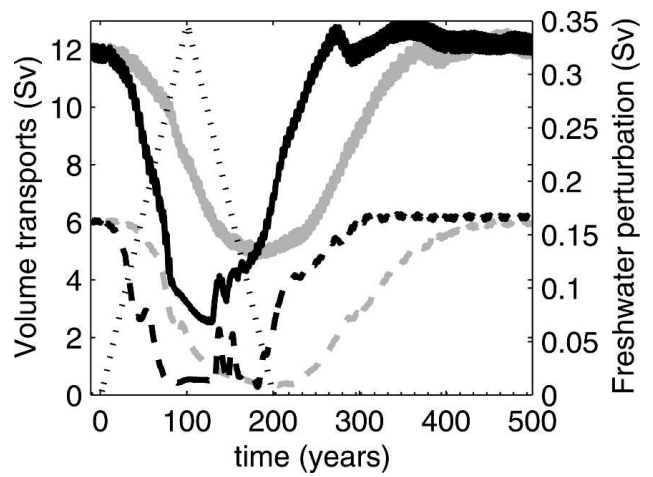

FIG. 12. As in Fig. 2a, but for the forcing scenario represented with the dotted black line (right scale). 
shutdown of the AMOC while Rühlemann et al. (2004) and Knutti et al. (2004) observed a warming. Our study sheds light on understanding these differences: the sign of the anomaly depends on whether intermediate ventilation continues or is shut down completely under freshwater perturbation and the magnitude and region of water hosing required to completely shut down intermediate water formation is model dependent. This might explain the apparent difference of our results with those from Manabe and Stouffer (1997). In their experiments where freshwater hosing is applied between $50^{\circ}$ and $70^{\circ} \mathrm{N}$, a strong subsurface cooling developed, while in similar experiment S-5080N, we found a subsurface warming. A possible explanation for this difference is that intermediate convection was still active in their experiment, which should thus rather be compared to our S-2050N experiment, where we also find subsurface cooling. The CMIP intercomparison involves both models of intermediate complexity and fully coupled general circulation models (Stouffer et al. 2006). Subsurface anomalies induced in response to the application of $0.1 \mathrm{~Sv}$ of anomalous freshwater over the deep-water formation region are very weak because the freshwater perturbation is not sufficient to significantly alter the overturning. However, warm anomalies are a general feature of the subsurface temperature structure in response to the application of $1 \mathrm{~Sv}$ of anomalous freshwater over the deep convection sites of the models, that is, when deep convection is off in all models (J. Yin 2005, personal communication). Using a climate model of intermediate complexity with glacial boundary conditions, Flueckiger et al. (2006) find a strong subsurface cooling for a freshwater perturbation of 0.2 Sv (as compared to an on-state with the same freshwater flux), and a subsurface warming for a large freshwater flux $(0.4 \mathrm{~Sv})$. This differs from our results, where the sign of the subsurface anomaly does not depend on the strength of freshwater forcing. It is unclear whether this is due to differences between the models or if it is related to the different climate states.

We showed that the subsurface temperature structure has crucial implications for the recovery of the AMOC once the freshwater perturbation is removed. When a warm reservoir has developed in subsurface, the recovery occurs on decadal time scales. Indeed, SSS rises rapidly and, with the help of wind-driven upwelling, the water column can be easily destabilized. This gives rise to intense flushes of deep-water formation that evacuate the warm subsurface anomaly very quickly through air-sea interactions and erode the surface fresh anomaly. These initial flushes allow a rapid increase of the subsurface northward density gradient.
A sustainable AMOC and permanent deep-water formation in the North Atlantic thus occur within another decade. In experiments where the AMOC was perturbed in midlatitudes, and where subsurface cold anomalies were maintained by intermediate depth ventilation, the AMOC recovery is much more gradual (typically over a century). It is the weak and shallow residual circulation associated with this ventilation that progressively evacuates the freshwater and brings at the same time relatively salty tropical waters to the north.

These results where shown to be robust to various details of the experimental setup, such as the duration, magnitude, and time evolution of the freshwater perturbation, and the oceanic vertical mixing. They are consistent with Stouffer and Manabe (2003) who underlined the influence of temperature distribution in subsurface and deeper layers of the Atlantic Ocean on the final state of the AMOC. Furthermore, we believe that they can help understanding and interpreting the diversity of the models' responses to hosing experiments and in particular the AMOC recovery (Stouffer et al. 2006). We emphasize that the relatively "slow" recovery observed in S-2050N is in fact typical for most water hosing experiments. It is associated with a positive advection-salinity feedback as already discussed by Rahmstorf (1996) or Goelzer et al. (2006). The real novelty here is the relatively fast (decadal time scales) recovery detected in S-5080N. The mechanism is initiated by an abrupt startup of convection in the high latitudes, which leads to fast initial recovery of the AMOC. Only after that does the salinity advection feedback come into play. Thus, the decadal recovery time scale in S-5080N is explained as the time scale of baroclinic adjustment to imposed density changes. In S-2050N, a complete recovery of the AMOC can only happen after a complete overturning of Atlantic water masses, that is, indeed on a centennial time scale.

The experiments were carried out with a climate model of intermediate complexity, and we cannot rule out that atmospheric variability (missing in CLIMBER$3 \alpha$ ) might be important for the subsurface temperature anomalies. However, a strong subsurface warming was also reported by Knutti et al. (2004) who used the ECBILT-CLIO model, which has a rather realistic extratropical variability. Moreover, the results of the 1-Sv hosing show a subsurface warming in all the coupled GCMs of the CMIP experiment (J. Yin 2005, personal communication). Finally, SST anomalies are very similar in both runs (Figs. 3a,b), so that we do not expect strong differences in the atmospheric response of the two experiments. Therefore, we do not believe that our results are just an artifact due to missing atmospheric 
variability. On the other hand, missing atmospheric feedback could possibly be important for the fast recovery mechanism. In particular, Schiller et al. (1997) find an important feedback of SST anomalies on the atmospheric cyclonic circulation over the Norwegian Sea. In their model, this feedback stabilizes deep-water formation in the North Atlantic. More generally, differences in the mean climate state might also be important for the impact of anomalous freshwater input, both in terms of subsurface temperature response and in terms of MOC recovery.

Beyond these modeling results, our findings have a series of more general implications. In particular, large subsurface temperature anomalies associated with a possible future reduction of the AMOC can have significant geochemical impacts (e.g., for the stability of the ocean clathrates reservoir). In the present climate, the latter are present at a depth of several hundred meters and below and several studies have shown that a warming of several degrees would strongly affect their stability. (e.g., Archer and Buffett 2005; Schicks et al. 2006). Furthermore, although our results were obtained in idealized water hosing experiments performed for modern climate conditions, they may also have important implications for understanding mechanisms of abrupt climate changes during the last glacial cycle. Our results demonstrate that if convection and ventilation are completely suppressed in the high latitudes of the North Atlantic by enhanced freshwater flux, the recovery of the AMOC after cessation of anomalous freshwater flux occurs abruptly and air temperature rises within several decades by about $6 \mathrm{~K}$ on average over the northern North Atlantic. When the perturbation is applied for a sufficiently long period, AMOC, overflow, and air temperature even overshoot their equilibrium values. This resembles the dynamics of the DansgaardOeschger warm events recorded during the last glacial cycle in Greenland and other locations, and corroborates the results of simulations of Dansgaard-Oeschger events obtained with two-dimensional ocean models (Winton 1997; Ganopolski and Rahmstorf 2001). Interestingly enough, a pronounced warming of the subsurface water masses during cold (stadial) conditions in the Nordic Seas was reported by Rasmussen and Thomsen (2004), though the interpretation of benthic isotopes remains ambiguous. Additional simulations, especially using glacial climate conditions, would be needed to corroborate applicability of our results to the mechanism of Dansgaard-Oeschger events. In particular, some of the Dansgaard-Oeschger events last $3000 \mathrm{yr}$ or more and show a decreasing trend over the whole interstadial. An overshooting phenomenon will probably not last for such a long time period. This implies that other factors are important in setting the shape of the events.

Another interesting implication of our results is related to the timing of the massive iceberg discharges into the North Atlantic. Recently, Moros et al. (2002) proposed that increased iceberg discharge during cold stadial events may have resulted from the destabilization of marine ice shelves by a strong subsurface melting caused, in turn, by enhanced oceanic heat transport. Alternatively, our results suggest that a considerable subsurface warming might be caused by a complete cessation of intermediate ventilation during periods of decreased northward heat transport and the maximum cooling in the Northern Hemisphere. This idea was first introduced by Shaffer et al. (2004), even though subsurface warming in this simplified model as well as in Winton's (1997) deep-coupling-decoupling oscillations reach much deeper down (about $3000 \mathrm{~m}$ ) than in the experiments shown here. The link between subsurface warming and cessation of intermediate ventilation is further supported by recent findings of Flueckiger et al. (2006). In particular, this mechanism sheds some light on the long-standing problem-why ice-rafted events (including Heinrich events) always occurred during cold (stadial) conditions in the North Atlantic. Here again, glacial simulations are required for a more definitive conclusion. One possible scenario is that the initial suppression of deep-water formation and establishing of a strong halocline in the glacial Nordic Seas are caused by melting or small-scale instability of surrounding ice sheets and ice caps. As soon as the ventilation is ceased completely, a subsurface warming starts to develop and via intense bottom melting of marine ice shelves provokes a large-scale instability of the Laurentide ice sheets. This might explain an apparent synchrony of ice-rafted events observed in different locations during the glacial age. The basal melting of ice shelves, whose depth ranges from a few hundred of meters to more than $1 \mathrm{~km}$ for the modern climate (Antarctica), is indeed very sensitive to the water temperature and increases by $10 \mathrm{~m} \mathrm{yr}^{-1}$ for each $1 \mathrm{~K}$ of water temperature rise (e.g., Rignot and Jacobs 2002). Thereby if the subsurface temperature rose during glacial stadials by $0-5 \mathrm{~K}$, it could lead to a complete melting of ice shelf in a matter of decades. While the mechanism of teleconnection between different ice sheets is promising, one has to admit that the degree of coupling between grounded ice and ice shelves remains a controversial issue.

Acknowledgments. JM and AL were funded by the Gary Comer foundation. The authors would also like to 
thank S. Rahmstorf for useful comments and J. Yin for providing additional results of the CMIP.

\section{REFERENCES}

Archer, D., and B. Buffett, 2005: Time-dependent response of the global ocean clathrate reservoir to climatic and anthropogenic forcing. Geochem. Geophys. Geosyst., 6, Q03002, doi:10.1029/2004GC000854.

Bond, G., and Coauthors, 1992: Evidence for massive discharge of icebergs into the North Atlantic Ocean during the last glacial. Nature, 360, 245-249.

Broccoli, A. J., K. A. Dahl, and R. J. Stouffer, 2006: Response of the ITCZ to Northern Hemisphere cooling. Geophys. Res. Lett., 33, L01702, doi:10.1029/2005GL024546.

Church, J. A., J. M. Gregory, P. Huybrechts, M. Kuhn, K. Lambeck, M. T. Nhuan, D. Qin, and P. L. Woodworth, 2001: Change in sea level. Climate Change 2001: The Scientific Basis, J. T. Houghton et al., Eds., Cambridge University Press, 640-693.

Clarke, P. U., N. G. Pisias, T. F. Stocker, and A. J. Weaver, 2002: The role of the thermohaline circulation in abrupt climate change. Nature, 415, 863-869.

Crowley, T. J., 1992: North Atlantic deep water cools the southern hemisphere. Paleoceanography, 7, 489-497.

Dickson, B., I. Yashayaev, J. Meincke, B. Turrell, S. Dye, and J. Holfort, 2002: Rapid freshening of the deep North Atlantic Ocean over the past four decades. Nature, 416, 832-837.

Fanning, A. F., and A. J. Weaver, 1997: Temporal-geographical meltwater influences on the North Atlantic Conveyor: Implications for the Younger Dryas. Paleoceanography, 12, 307320.

Fichefet, T., and M. A. M. Maqueda, 1997: Sensitivity of a global sea ice model to the treatment of ice thermodynamics and dynamics. J. Geophys. Res., 102, 12 609-12 646.

Flueckiger, J., R. Knutti, and J. W. C. White, 2006: Oceanic processes as potential trigger and amplifying mechanisms for Heinrich Events. Paleoceanography, 21, PA2014, doi:10.1029/ 2005PA001204.

Ganachaud, A., and C. Wunsch, 2000: Improved estimates of global ocean circulation, heat transport and mixing from hydrographic data. Nature, 408, 453-456.

Ganopolski, A., and S. Rahmstorf, 2001: Rapid changes of glacial climate simulated in a coupled climate model. Nature, 409, 153-158.

Goelzer, H., J. Mignot, A. Levermann, and S. Rahmstorf, 2006: Tropical versus high latitude freshwater influence on the thermohaline circulation. Climate Dyn., 27, 715-725.

Gregory, J. M., O. A. Saenko, and A. J. Weaver, 2003: The role of the Atlantic freshwater balance in the hysteresis of the meridional overturning circulation. Climate Dyn., 21, 707-717.

Hasumi, H., and N. Suginohara, 1999: Effects of locally enhanced vertical diffusivity over rough bathymetry on the world ocean circulation. J. Geophys. Res., 104, 23 364-23 374.

Heinrich, H., 1988: Origin and consequences of cyclic ice rafting in the northeastern Atlantic Ocean during the past 130,000 years. Quat. Res., 29, 142-152.

Herweijer, C., R. Seager, M. Winton, and A. Clement, 2005: Why ocean heat transport warms the global mean climate. Tellus, 57A, 662-675.

Hofmann, M., and M. A. M. Maqueda, 2006: Performance of a second-order moments advection scheme in an Ocean Gen- eral Circulation Model. J. Geophys. Res., 111, C05006, doi:10.1029/2005JC003279.

Houghton, J. T., Y. Ding, D. J. Griggs, M. Noguer, P. J. van der Linden, X. Dai, K. Maskell, and C. A. Johnson, Eds., 2001: Climate Change 2001: The Scientific Basis. Cambridge University Press, $881 \mathrm{pp}$.

Kalnay, E., and Coauthors, 1996: The NCEP/NCAR 40-Year Reanalysis Project. Bull. Amer. Meteor. Soc., 77, 437-471.

Knutti, R., J. Flueckiger, T. F. Stocker, and A. Timmernmann, 2004: Strong hemispheric coupling of glacial climate through freshwater discharge and ocean circulation. Nature, 430, 851856.

Large, W. G., J. C. McWilliams, and J. C. Doney, 1994: Oceanic vertical mixing: A review and a model with a nonlocal boundary layer parameterization. Rev. Geophys., 32, 363-403.

Ledwell, J. R., E. T. Montgomery, K. L. Polzin, L. C. St. Laurent, R. W. Schmitt, and J. M. Toole, 2000: Evidence for enhanced mixing over rough topography in the abyssal ocean. Nature, 403, 179-182.

Levermann, A., and A. Griesel, 2004: Solution of a model for the oceanic pycnocline depth: Scaling of overturning strength and meridional pressure difference. Geophys. Res. Lett., 31, L17302, doi:10.1029/2004GL020678.

,-- M. Hofmann, M. Montoya, and S. Rahmstorf, 2005: Dynamic sea level changes following changes in the thermohaline circulation. Climate Dyn., 24, 347-354.

Luyten, J. R., J. Pedlosky, and H. Stommel, 1983: The ventilated thermocline. J. Phys. Oceanogr., 13, 292-309.

Manabe, S., and R. J. Stouffer, 1988: Two stable equilibria of a coupled ocean-atmosphere model. J. Climate, 1, 841-866.

-, and 1993: Century-scale effects of increased atmospheric $\mathrm{CO}_{2}$ on the ocean-atmosphere system. Nature, 364, 215-218.

—, and - 1995: Simulation of abrupt climate change induced by freshwater input to the North Atlantic Ocean. $\mathrm{Na}$ ture, 378, 165-167.

— , and _ 1997: Coupled ocean-atmosphere model response to freshwater input: Comparison to Younger Dryas event. Paleoceanography, 12, 321-336.

McManus, J. F., R. Francois, J.-M. Gherardi, L. D. Keigwin, and S. Brown-Leger, 2004: Collapse and rapid resumption of Atlantic meridional circulation linked to deglacial climate changes. Nature, 428, 834-837.

Mignot, J., A. Levermann, and A. Griesel, 2006: A decomposition of the Atlantic meridional overturning circulation into physical components using its sensitivity to vertical diffusivity. $J$. Phys. Oceanogr., 36, 636-650.

Montoya, M., A. Griesel, A. Levermann, J. Mignot, M. Hofmann, A. Ganopolski, and S. Rahmstorf, 2005: The Earth system model of intermediate complexity CLIMBER- $3 \alpha$. Part I: Description and performance for present day conditions. Climate Dyn., 25 (2-3), 237-263.

Moros, M., A. Kuijpers, I. Snowball, S. Lassen, D. Bäckström, F. Gingele, and J. McManus, 2002: Were glacial iceberg surges in the North Atlantic triggered by climatic warming? Mar. Geol., 192, 393-417.

Peterson, B. J., R. M. Holmes, J. W. McClelland, C. J. Vörösmarty, R. B. Lammers, A. I. Shiklomanov, I. A. Shiklomanov, and S. Rahmstorf, 2002: Increasing river discharge to the Arctic Ocean. Science, 298 (5601), 2171-2173.

Peterson, L. C., G. H. Haig, K. A. Hughen, and U. Röhl, 2000: Rapid changes in the hydrologic cycle of the tropical Atlantic during the last glacial. Science, 290, 1947-1951. 
Petoukhov, V., A. Ganopolski, V. Brovkin, M. Claussen, A. Eliseev, C. Kubatzki, and S. Rahmstorf, 2000: CLIMBER 2: A climate system model of intermediate complexity. Part I: Model description and performance for present climate. Climate Dyn., 16, 1-17.

Prather, M. J., 1986: Numerical advection by conservation of second-order moments. J. Geophys. Res., 91, 6671-6681.

Rahmstorf, S., 1996: On the freshwater forcing and transport of the Atlantic thermohaline circulation. Climate Dyn., 12, 799811.

_- 2002: Ocean circulation and climate during the past 120, 000 years. Nature, 419, 207-214.

_ , and A. Ganopolski, 1999: Long-term global warming scenarios computed with an efficient coupled climate model. Climatic Change, 43, 353-367.

- and Coauthors, 2005: Thermohaline circulation hysteresis: A model intercomparison. Geophys. Res. Lett., 32, L23605, doi:10.1029/2005GL023655.

Rasmussen, T. L., and E. Thomsen, 2004: The role of the North Atlantic Drift in the millennial timescale glacial climate fluctuations. Palaeogeogr. Palaeoclimatol. Palaeoecol., 210, 101116.

Rignot, E., and S. S. Jacobs, 2002: Rapid bottom melting widespread near Antarctic ice sheet grounding lines. Science, 296, 2020-2023.

Rind, D., G. Russell, G. Schmidt, S. Sheth, D. Collins, P. deMenocal, and J. Teller, 2001: Effects of glacial meltwater in the GISS coupled atmosphere-ocean model 2. A bipolar seesaw in Atlantic Deep Water production. J. Geophys. Res., 106, 27 355-27 365.

Rühlemann, C., S. Mulitza, G. Lohmann, A. Paul, M. Prange, and G. Wefer, 2004: Intermediate depth warming in the tropical Atlantic related to weakened thermohaline circulation: Combining paleoclimate data and modelling results for the last deglaciation. Paleoceanography, 19, PA1025, doi:10.1029/ 2003PA000948.

Schicks, J. M., R. Naumann, J. Erzinger, K. C. Hester, C. A. Koh, and E. D. Sloan Jr., 2006: Phase transitions in mixed gas hy- drates: Experimental observations versus calculated data. $J$. Phys. Chem. B, 110, 11 468-11 474.

Schiller, A., U. Mikolajewicz, and R. Voss, 1997: The stability of the North Atlantic thermohaline circulation in a coupled ocean-atmosphere general circulation model. Climate Dyn., 13, 325-347.

Shaffer, G., S. Malskaer Olsen, and C. J. Bjerrum, 2004: Ocean subsurface warming as a mechanism for coupling DansgaardOeschger climate cycles and ice-rafting events. Geophys. Res. Lett., 31, L24202, doi:10.1029/2004GL020968.

Stocker, T. F., 1998: The seesaw effect. Science, 282, 61-62.

—, and D. G. Wright, 1991: Rapid transitions of the ocean's deep circulation induced by changes in surface water fluxes. Nature, 351, 729-732.

Stommel, H. M., 1961: Thermohaline convection with two stable regimes of flow. Tellus, 13, 224-230.

Stouffer, R. J., and S. Manabe, 2003: Equilibrium response of thermohaline circulation to large changes in atmospheric $\mathrm{CO}_{2}$ concentration. Climate Dyn., 20, 759-773.

- , and Coauthors, 2006: Investigating the causes of the response of the thermohaline circulation to past and future climate changes. J. Climate, 19, 1365-1387.

Timmermann, A., S.-I. An, U. Krebs, and H. Goosse, 2005: ENSO suppression due to weakening of the North Atlantic thermohaline circulation. J. Climate, 18, 3122-3139.

Trenberth, K. E., and J. M. Caron, 2001: Estimates of meridional atmosphere and ocean heat transports. J. Climate, 14, 3433 3443.

Vellinga, M., and R. Wood, 2002: Global climatic impacts of a collapse of the Atlantic thermohaline circulation. Climatic Change, 54, 251-267.

Wang, Z., 2005: Two climatic states and feedbacks on thermohaline circulation in an Earth system model of intermediate complexity. Climate Dyn., 25, 299-314.

Winton, M., 1997: The effect of cold climate upon North Atlantic Deep Water formation in a simple ocean-atmosphere model. J. Climate, 10, 37-51.

, 2003: On the climatic impact of ocean circulation. J. Climate, 16, 2875-2889. 